\title{
Effective Biopesticides and Biostimulants to Reduce Aflatoxins in Maize Fields
}

\section{Christina S. Lagogianni and Dimitrios I. Tsitsigiannis*}

Laboratory of Plant Pathology, Department of Crop Science, School of Plant Sciences, Agricultural University of Athens, Athens, Greece

The presence of ear rots in maize caused by Aspergillus flavus that are also associated with the production of aflatoxins has evolved into an increasing problem over the last few years. Since no commercial biological control products are still available to control A. flavus in maize in Europe, this study targets to the evaluation of six biopesticides/ biostimulants (Botector ${ }^{\circledR}$, Mycostop $^{\circledR}$, Serenade Max ${ }^{\circledR}$, Trianum ${ }^{\circledR}$, Vacciplant ${ }^{\circledR}$, and zeolite) for the control of $A$. flavus and the derived aflatoxins in in vitro and maize field bioassays. Mycostop ${ }^{\circledR}$, Serenade Max ${ }^{\circledR}$, Vacciplant ${ }^{\circledR}$, and zeolite reduced significantly A. flavus conidia production by 38.8-63.1\%, and most of them were able to reduce aflatoxin B1 (AFB1) production in laboratory studies. Mycostop ${ }^{\circledR}$, Trianum ${ }^{\circledR}$, and Botector ${ }^{\circledR}$ were effective in reducing AFB1, in vitro. In the field, Mycostop ${ }^{\circledR}$ and Botector ${ }^{\circledR}$ treatments resulted in significant reduction of the disease severity (16.5 and 21.9\%, respectively) and decreased significantly AFB1 content in maize kernels by 43.05 and $43.09 \%$, respectively. For the first time, these results demonstrated the potential of commercial non-chemical products to suppress disease symptoms and aflatoxin content caused by $A$. flavus in maize under laboratory and field conditions.

Keywords: Aspergillus ear rot, aflatoxins, Aspergillus flavus, biological control, mycotoxins

\section{INTRODUCTION}

Mycotoxins are toxic metabolites of low molecular weight that are produced by several species of mycotoxigenic fungi. A plethora of mycotoxins which are differing in their chemical structure have been identified, but all of them have the same common characteristics; they contaminate food and animal feed causing chronic toxicity and lead to more than $25 \%$ of agricultural products that are discarded annually (Bennett and Klich, 2003; CAST, 2003). One of the most common mycotoxigenic fungi is Aspergillus flavus, a predominant plant pathogen of maize (Zea mays L.) causing destructive plant diseases commonly known as ear rots and capable of contaminating maize kernels with aflatoxins (AFs). Toxigenic strains of A. flavus produce primarily the AFB1 and AFB2, although other mycotoxins (AFG1, AFG2, cyclopiazonic acid) can also be produced by the same species (Dorner and Cole, 2002; Dorner and Horn, 2007). AFs are worldwide one of the major threats to food 
quality and safety of the population feed. They are in first place $(44 \%)$ as a reason for rejecting imports of various products in EU (RASFF/Rapid Alert System For Food and Feed for the European Union, 2008). Infection of maize by aflatoxigenic strains of $A$. flavus is favored by hot climatic conditions and the risk of aflatoxin biosynthesis is increased due to the dry and warm climate conditions combined with inappropriate storage conditions (Chulze, 2010).

Various strategies including chemical and biological control, development of tolerant varieties and control of insects that favor Aspergillus infection have been investigated in the effort to manage aflatoxins (AFs) in crops and agricultural products. Among them, biological control appears a very promising approach to control AFs at pre- and post-harvest level (Udomkun et al., 2017). In maize, the most susceptible stage for infection is during anthesis. Consequently, the most appropriate stage for application of biological or chemical plant protection products is this stage of ear development not only to protect wounds or plant surfaces, but also to give the biocontrol agents the ability to compete plant pathogens for space and nutrients (Vaughan et al., 2005; Dimakopoulou et al., 2008; Ponsone et al., 2011).

Numerous microorganisms including bacteria, yeasts, and non-toxigenic fungi of $A$. flavus have been evaluated for their ability to manage AF contamination in crops including maize, intending to reduce the impact of aflatoxigenic species (Yin et al., 2008; Ponsone et al., 2011; Mauro et al., 2018). Dorner (2004) and Atehnkeng et al. (2014) reported the efficacy of atoxigenic A. flavus strains in preventing AF contamination in maize field. Over time, several other effective non-toxigenic fungal strains have been commercialized like $\mathrm{AF}-\mathrm{X}{ }^{\circledR}$ in Italy for aflatoxin management in maize (Mauro et al., 2018). In another study, it was reported the efficacy of two Bacillus strains in the control of A. parasiticus and aflatoxins production on pistachio (Siahmoshteh et al., 2017). Moreover, Chourasia and Sah (2017) pointed out the successful control of A. flavus and $\mathrm{AF}$ production with geocarposphere bacteria in peanuts in greenhouse experiments. In addition, Sivparsad and Laing (2016) showed that pre-harvest silk treatment with Trichoderma harzianum reduced disease severity and AF contamination caused by A. flavus in sweet corn, in greenhouse, and field experiments.

The use of biological agents and biostimulants for the control of A. flavus is a prerequisite for creating an Integrated Pest Management (IPM) in order to protect maize from AF contamination. Commercial biopesticides could offer an economically effective solution that will contribute to the exclusion of aflatoxigenic fungi from maize plants and the restriction of mycotoxin production with the help of an IPM system that will be friendly and sustainable for the environment. Mycotoxin control and reduction is crucial for food safety, animal welfare, human health reasons, and production economics (Bennett and Klich, 2003; CAST, 2003; Bosco and Mollea, 2012). In spite of the high contamination risk of maize by mycotoxigenic fungi and mycotoxins, biological control studies conducted on this particular crop are limited and most of them refer to in vitro results. This study suggests a biocontrol strategy based on commercial plant protection products to reduce AF contamination in maize fields. Therefore, the aim of the present study was: (1) to test the efficacy of six biopesticides/biostimulants, to inhibit conidiogenesis and aflatoxin production in vitro, and (2) to evaluate the potential of the most efficient products to reduce $A$. flavus infection and aflatoxin contamination of maize under field conditions.

\section{MATERIALS AND METHODS}

\section{Fungal Strains and Culture Conditions}

Three A. flavus isolates were used in the experiments: A 6.10, D 1.3, and 12S. The isolates A 6.10 and D 1.3 originate from maize fields and pistachio orchards, respectively, in Greece and held in the culture collection of the Laboratory of Plant Pathology, Department of Crop Science, Agricultural University of Athens, whereas $12 \mathrm{~S}$ originate from a cotton field in the USA. The isolates were mixed with glycerol (AppliChem, Darmstadt, Germany) to a final glycerol concentration of $25 \%$ $(\mathrm{v} / \mathrm{v})$ and stored at $-20^{\circ} \mathrm{C}$. The molecular characterization and the determination of aflatoxigenic efficacy of A 6.10, D 1.3 , and $12 \mathrm{~S}$ strains are described in our previous study (O’Donnell, 2000; Lagogianni and Tsitsigiannis, 2018).

\section{Biocontrol Products - Biopesticides/ Biostimulants}

Six products containing microorganisms or inorganic components with various modes of actions against a range of plant pathogens (Table 1) were used in bioassays: (1) zeolite, a microporous aluminosilicate mineral with special physicochemical properties, (2) Trianum ${ }^{\circledR}$, a commercial product that contains the fungus Trichoderma harzianum and acts by inhibiting the infection and colonization of pathogenic fungi and inducing the plant defense system, (3) Botector ${ }^{\circledR}$, a commercial product that

TABLE 1 | Commercial biopesticides and biostimulants used in the present study, active ingredients and applied doses according to manufacturer's instructions and company.

\begin{tabular}{|c|c|c|c|}
\hline Product name & $\begin{array}{l}\text { Active } \\
\text { ingredient/ } \\
\text { biological agent }\end{array}$ & Applied dosage $^{a}$ & Company \\
\hline Botector $^{\circledR}$ & $\begin{array}{l}\text { Aureobasidium } \\
\text { pullulans strains }\end{array}$ & $1 \mathrm{~g} \mathrm{~L}^{-1}$ & BIO-FERM $^{\circledast}$ \\
\hline Trianum ${ }^{\circledR}$ & $\begin{array}{l}\text { Trichoderma } \\
\text { harzianum }\end{array}$ & $3 \mathrm{~g} \mathrm{~L}^{-1}$ & Koppert $^{\circledR}$ \\
\hline Mycostop ${ }^{\circledast}$ & $\begin{array}{l}\text { Streptomyces } \\
\text { griseoviridis }\end{array}$ & $0.5 \mathrm{~g} \mathrm{~L}^{-1}$ & Verdera $^{\circledR}$ \\
\hline Serenade $\mathrm{Max}^{\circledR}$ & $\begin{array}{l}\text { Bacillus subtilis } \\
\text { QST } 713\end{array}$ & $4 \mathrm{~g} \mathrm{~L}^{-1}$ & $\mathrm{BASF}^{\circledR}$ \\
\hline Zeolite $^{\circledR}$ & Mineral & $10 \mathrm{~g} \mathrm{~L}^{-1}$ & Olympos ${ }^{\circledast}$ \\
\hline Vacciplant $^{\circledR}$ & Laminarine & $2 \mathrm{~g} \mathrm{~L}^{-1}$ & GOEMAR $^{\circledast}$ \\
\hline
\end{tabular}

${ }^{a}$ Highest recommended dosage according to manufacturer's instructions. 
contains yeasts of Aureobasidium pullulans with proven activity against Botrytis cinerea in grapes, (4) Mycostop ${ }^{\circledast}$, a biological fungicide developed from the naturally occurring bacterium Streptomyces griseoviridis that provides biological protection against root infecting pathogenic fungi, (5) Serenade $\operatorname{Max}^{\circledR}$, a commercial product that contains the bacterium Bacillus subtilis strain QST 713 with bio-fungicide/bio-bactericide action that stimulates natural plant defense mechanisms and demonstrates increased plant growth effects, and (6) Vacciplant ${ }^{\circledR}$, which bases its action on activating the plant defenses thanks to the action of laminarine, a storage glucan from Laminaria digitata. All the above mentioned agents were initially tested in vitro and the most efficient were further evaluated in 2-year experiments under field conditions.

\section{In vitro Evaluation of Biopesticides and Biostimulants on Aspergillus flavus Sporulation and Aflatoxin Production}

The effect of the tested biopesticides and biostimulants on A. flavus sporulation and AFs production was initially studied in vitro. To conduct the bioassays, $40 \mathrm{~g}$ corn seeds (maize line N9, House of Agriculture Spirou, Athens, Greece) were surface-sterilized by immersing them in $10 \% \mathrm{NaClO}$ for $10 \mathrm{~min}$, washed briefly with sterile distilled water (SDW), placed in $70 \% \mathrm{ETOH}$ for $3 \mathrm{~min}$, and washed again with SDW for each biological product. The surface-sterilization of the seeds was carried out to avoid contamination from the seed surface saprophytes and keep the corn kernels alive. The seeds were not autoclaved to avoid the inactivation of the natural seed tolerance/resistance to Aspergillus infection provided by the plant immune system. Then, seeds for each treatment were placed into $250 \mathrm{ml}$ capacity flasks containing each commercial product at the appropriate concentration according to the dose recommended by manufacturer's instructions (Table 1). The flasks were shaken at $250 \mathrm{rpm}$ for $30 \mathrm{~min}$, then the solutions were discarded and corn seeds were kept at room temperature for $24 \mathrm{~h}$. Then, seeds were artificially inoculated by adding in each flask $50 \mathrm{ml}$ of $A$. flavus conidial suspension $\left(10^{6}\right.$ conidia $\left.\mathrm{ml}^{-1}\right)$ and shaking at $250 \mathrm{rpm}$ for $30 \mathrm{~min}$ (Lagogianni and Tsitsigiannis, 2018). The suspension was removed and the flasks were placed at $28^{\circ} \mathrm{C}$ in the dark for 13 days to let the fungus produce AFB1. The presence of AFB1 in each sample was determined with thin layer chromatography (TLC) method, according to the following procedure: the seeds were grinded and 3 $\mathrm{g}$ of the fine powder were transferred into $50 \mathrm{ml}$ falcon tubes, where $5 \mathrm{ml}$ Tween $80(0.01 \%)$ and $5 \mathrm{ml}$ acetone were consecutively added. The samples were shaken at $150 \mathrm{rpm}$ for $10 \mathrm{~min}$ and kept still for $5 \mathrm{~min}$ at room temperature; $5 \mathrm{ml}$ chloroform were added and further shaken at $150 \mathrm{rpm}$ for $10 \mathrm{~min}$. The samples were passed through a filter paper and the flow-through collected into a new tube. The flowthrough was centrifuged for $10 \mathrm{~min}$ at $3,000 \mathrm{rpm}$ and the lower phase transferred into a new tube and kept overnight at room conditions to dry-out. Finally, $100 \mu \mathrm{l}$ methanol were added and $10 \mu \mathrm{l}$ of the sample spotted on a TLC plate (TLC Silica gel 60, Merck, Germany). TLC plate development and AFB1 detection were determined as mentioned above (Scott, 1995). The AFB1 that used as standard was purchased from Sigma-Aldrich.

To study the effect of the different tested biopesticides/ biostimulants on the sporulation of $A$. flavus, each product was applied on corn seeds as described above and the seeds were placed in sterilized petri dishes (10 seeds per plate). Twenty-four hours later, one droplet of conidial suspension (10 $\mu \mathrm{l}$ of a $10^{6}$ conidia $\mathrm{ml}^{-1}$ ) of each A. flavus isolate (A 6.10, D1.3, and 12S) was deposited on each seed in the plate. Five days post inoculation, the 10 seeds of each plate were transferred in a new $50 \mathrm{ml}$ falcon tube and $10 \mathrm{ml}$ of sterilized distilled water was added. The samples were vortexed vigorously for $30 \mathrm{~s}$ and then the numbers of conidia were measured under a light microscope with the use of a Neubauer hemocytometer. The experiment was repeated three times, with 30 replicated maize seeds per treatment.

\section{Maize Field Experiments}

Two-year experiments were carried out in the same experimental field of Agricultural University of Athens, Greece, in 2014 and 2015 crop seasons. Corn seeds (maize hybrid N9, House of Agriculture Spirou, Athens, Greece) were sown in the soil in April 2014 and 2015. Vacciplant ${ }^{\circledR}$ and zeolite were applied once whereas Mycostop ${ }^{\circledR}$, Trianum ${ }^{\circledR}$, and Botector ${ }^{\circledR}$ were applied twice by using a nozzle sprayer: the first application was carried out at the beginning of the flowering stage whereas the second one 7 days later. The applied dosages for each product are presented in Table 1, while no additional adjuvant or surfactants were used. The artificial inoculation was performed according to Lagogianni and Tsitsigiannis, 2018. Briefly, $5 \mathrm{ml}$ of conidial suspension of $A$. flavus strain A6.10 ( $10^{6}$ conidia $\mathrm{ml}^{-1}$ in sterile $\mathrm{ddH}_{2} \mathrm{O}$ containing $0.05 \mathrm{~g} \mathrm{~L}^{-1}$ Tween 80 ) were injecting in maize ears using a $10 \mathrm{ml}$ capacity syringe with a needle. Three milliliter of the inoculum was injected through the silk into the top of each maize ear and $2 \mathrm{ml}$ through the husk into the middle of the ear at each of four points. Both inoculated and mock inoculated ears were immediately covered with paper bags for $48 \mathrm{~h}$ to maintain high humidity and favor Aspergillus infection (Zummo and Scott, 1989). The experiments were performed with a factorial randomized block design with three blocks and six experimental units (Control+, Botector, Trianum $^{\circledR}$, Vacciplant ${ }^{\circledR}$, Mycostop $^{\circledR}$, and zeolite) per block. Each experimental unit consisted of 30 replicated plants.

\section{Disease Assessment and AFB1 Analysis}

Disease symptoms were assessed at the end of each growing season (60 days post inoculation), in September 2014 and 2015. Disease severity index was based on a visual scale from 1 to 7 , considering the percentage of symptomatic kernels per ear $(1=$ healthy, $2=1-3 \%, 3=4-10 \%, 4=11-25 \%, 5=26-50 \%$, 
$6=51-75 \%$, and $7=76-100 \%)$ of infected kernels, respectively (Reid et al., 1999). Maize cobs were harvested and their kernels were detached and placed in a drying oven until their humidity reached 15-18\%. Then kernels were homogenized using a grinder and $40 \mathrm{~g}$ of the fine powder were used for AFB1 analysis, following the Agra-Quant aflatoxin 4-40ppb ELISA kit protocol (Romer-Labs).

\section{Statistical Analysis}

All experimental data were analyzed with SPSS statistical software (SPSS Inc., Chicago, IL, USA). Analysis of variance (ANOVA) was used to determine the effects of replication, treatment, year and their interaction on disease severity and AFs production in field experiments. In laboratory experiments, ANOVA was used to determine the effects of replication, treatment, and $A$. flavus isolate on conidia production. When a significant $F$-test was obtained for treatments $(p \leq 0.05)$, the data were subjected to means separation by Tukey's honestly significant difference (HSD) test (Table 2).

\section{RESULTS}

\section{Effect of Biological Products and Biostimulants on Aspergillus flavus Sporulation and Aflatoxin Production in vitro}

Among treatments, Vacciplant ${ }^{\circledR}$ was the most efficient in decreasing A. flavus sporulation in vitro, followed by Serenade $\operatorname{Max}^{\circledR}$, Mycostop $^{\circledR}$, and zeolite leading to a reduction of conidia production by $63.1,55.4,48.2$, and $52.1 \%$, respectively. Botector $^{\circledR}$ and Trianum ${ }^{\circledR}$ did not result in any significant reduction of fungal sporulation (Figure 1). Analysis of variance revealed that $A$. flavus isolates differed significantly in terms of sporulation ( $\mathrm{df}=2, F=3.23, p<0.05)$. Moreover, treatments effected significantly sporulation of the fungus in vitro $(\mathrm{df}=6, F=7.14, p<0.001)$.

The capacity of the biological products and biostimulants to eliminate the aflatoxin production was also evaluated. AF was extracted from infected maize seeds and the extracts were developed by TLC. TLC tests showed that Mycostop ${ }^{\circledR}$, Trianum $^{\circledR}$, and Botector ${ }^{\circledR}$ were very effective in reducing aflatoxin biosynthesis in vitro, produced by each toxigenic strain, whereas zeolite, Vacciplant ${ }^{\circledR}$, and Serenade Max $^{\circledR}$ did not provide a constant significant reduction in aflatoxin production (Figure 2).

Based on these results, Mycostop ${ }^{\circledR}$ contributed to the inhibition of the conidiogenesis and to a significant reduction in the AFB1 content for all the three tested A. flavus strains. Trianum $^{\circledR}$ inhibited AF production but did not have any statistically significant effect to the conidia production. Vacciplant ${ }^{\circledR}$, Serenade $\mathrm{Max}^{\circledR}$, and zeolite did not lead to any

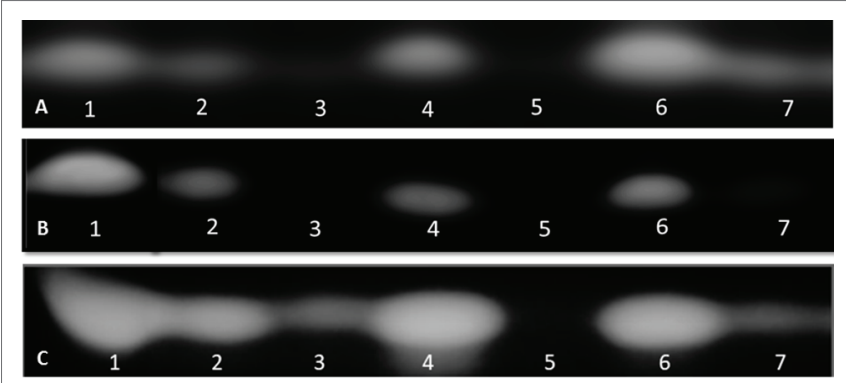

FIGURE 2 | TLC detection of AFB1 in maize seeds treated with various biopesticides/biostimulants 13 days post their artificial inoculation with the toxigenic isolates D1.3 (A), 12S (B), and A6.10 (C) of A. flavus (1: non-treated seeds that served as positive control, 2: seeds treated with Vacciplant ${ }^{\circledR}, 3$ : seeds treated with Botector ${ }^{\circledR}, 4$ : seeds treated with Serenade Max ${ }^{\circledR}, 5$ : seeds treated with Mycostop ${ }^{\circledR}, 6$ : seeds treated with zeolite, and 7: seeds treated with Trianum $^{\circledR}$ ).

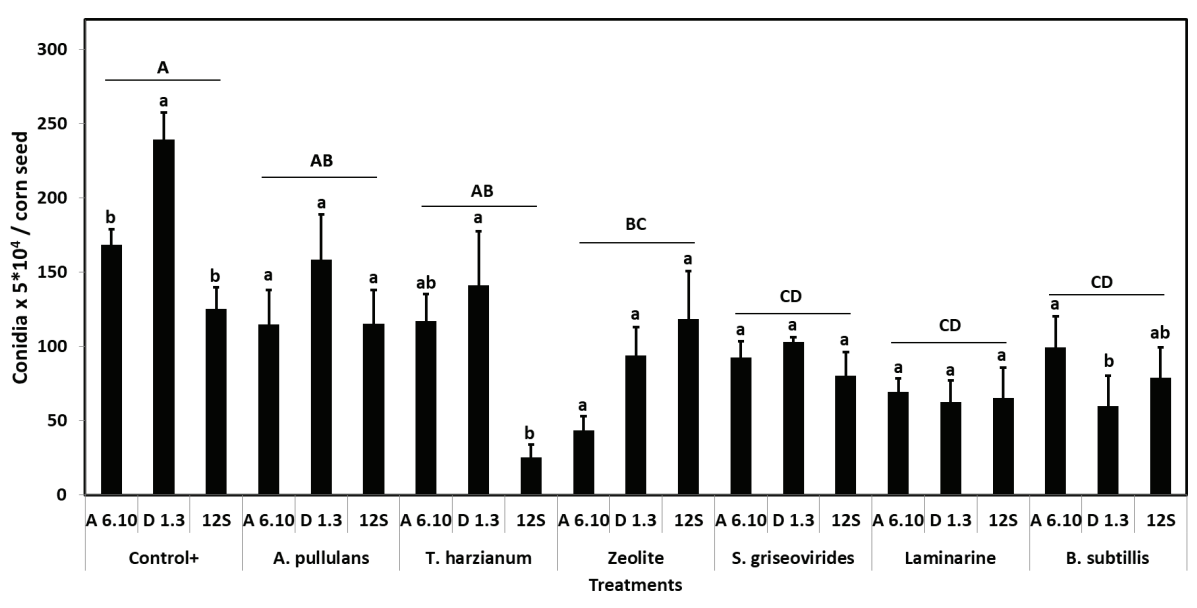

FIGURE 1 | Mean numbers of conidia production of $A$. flavus by the strains A6.10, D1.3, and 12S in maize seeds treated with different commercial biopesticides/ biostimulants. Within each treatment, columns with different lower-case letters differ significantly according to Tukey's HSD test ( $p \leq 0.05$ ). Different upper-case letters indicate significant differences between treatments according to Tukey's HSD test ( $p \leq 0.05)$. Each column represents the mean of three measurements per isolate and vertical bars indicate standard errors of the means. 
reduction in the AFB1 content (Figure 2) but the inhibition of $A$. flavus conidia production was significant in the case of zeolite and Vacciplant ${ }^{\circledR}$. Among the three strains, the conidiogenesis of D1.3 was not influenced significantly by the presence of the tested bioproducts except for the case of Serenade $\operatorname{Max}^{\circledR}$.

\section{Suppression of Ear Rot Disease Symptoms and AFB1 Production in the Field by the Use of Biopesticides/Biostimulants}

The toxigenic A6.10 maize strain, an isolate from Northern Greece, was used for the 2-year field experiments. Since Serenade $\mathrm{Max}^{\circledR}$ did not have a constant reduction of AFB1 in in vitro experiments, was not included in the field experiments. ANOVA revealed that neither experimental year nor the interaction between year and other experimental factors affected disease severity and AFB1 quantity significantly (Table 2). Therefore, data from 2-year experimentation (2014 and 2015) were combined and presented in Figure 3.

In order to evaluate the disease severity of infected maize ears under field conditions after the application of the commercial biopesticides/biostimulants, a scale of 1-7 was used (Reid et al., 1999). The disease severity index in plants treated with Mycostop ${ }^{\circledR}$ and Botector ${ }^{\circledR}$ was significantly lower compared to the Control+ plants (by 16.5 and 21.9\%, respectively), a fact that demonstrates the suppressive effect of the above mentioned products under field conditions (Figure 3). The observed decrease in symptom severity, in Mycostop $^{\circledR}$ and Botector ${ }^{\circledR}$ treated plants was also associated with significantly lower AFB1 content in maize kernels, by 43.05 and $43.09 \%$, respectively (Figure 4). Trianum ${ }^{\circledR}$ and Vacciplant ${ }^{\circledR}$ treated plants did not provide any statistically significant reduction on the AFB1 content, but offered a reduction in the disease severity whereas zeolite did not have any influence on either the disease severity or the AF content of maize ears.

TABLE 2 | Analysis of variance for disease severity and aflatoxin (AFB1) quantity in maize plants artificially inoculated with $A$. flavus isolate A6.10, treated with commercial biopesticides based on A. pullulans (Botector $\left.{ }^{\circledR}\right)$, S. griseovirides (Mycostop ${ }^{\oplus}$ ), Zeolite ${ }^{\circledR}$, laminarine (Vacciplant ${ }^{\oplus}$ ), and T. harzianum (Trianum ${ }^{\circledR}$ ) or not (positive control), under field conditions in 2014 and 2015.

\begin{tabular}{lccc}
\hline Source & $\mathbf{d f}^{\mathbf{b}}$ & \multicolumn{2}{c}{$\boldsymbol{F}^{\text {values }}{ }^{\mathbf{a}}$} \\
\cline { 3 - 4 } & & Disease severity & AFB1 \\
\hline Replication & 2 & 1.66 & - \\
Treatment & 5 & $23.30^{\star \star \star}$ & $19.95^{\star \star \star}$ \\
Year & 1 & 0.13 & 0.28 \\
Replication $\times$ Treatment & 10 & $3.02^{*}$ & - \\
Replication $\times$ Year & 2 & 0.28 & - \\
Treatment $\times$ Year & 5 & 1.40 & 0.29 \\
Replication $\times$ Treatment $\times$ Year & 10 & 0.26 & - \\
& & &
\end{tabular}

aSymbols: * and ${ }^{* * *}$ indicate significance at $p \leq 0.05$ and 0.001 levels, respectively, according to the $F$ test.

${ }^{b}$ Degrees of freedom between groups.

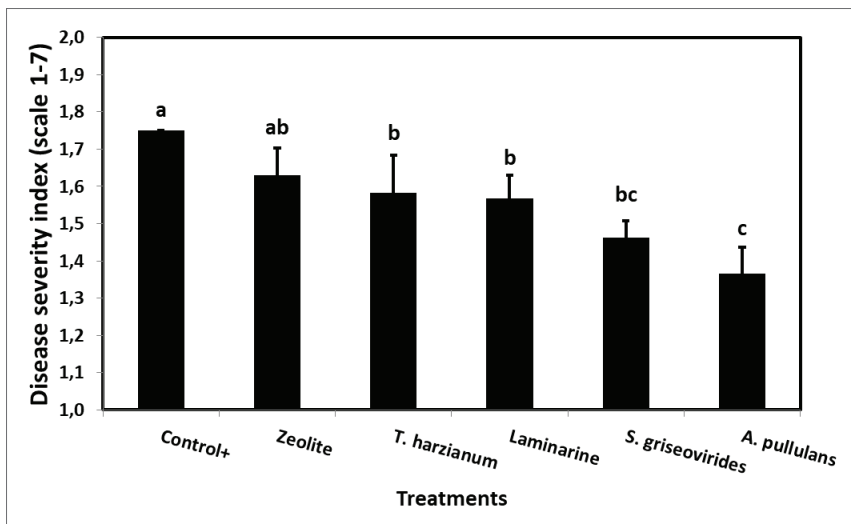

FIGURE 3 | Mean Aspergillus ear rot severity indices on field grown maize plants treated with different commercial biopesticides/biostimulants and artificially infected by $A$. flavus maize strain A6.10. Columns followed by different letters are significantly different ( $p \leq 0.05)$, according to Tukey's HSD test. Vertical bars indicate standard errors of the means. The results represent the average Aspergillus ear rot severity for 2014 and 2015.

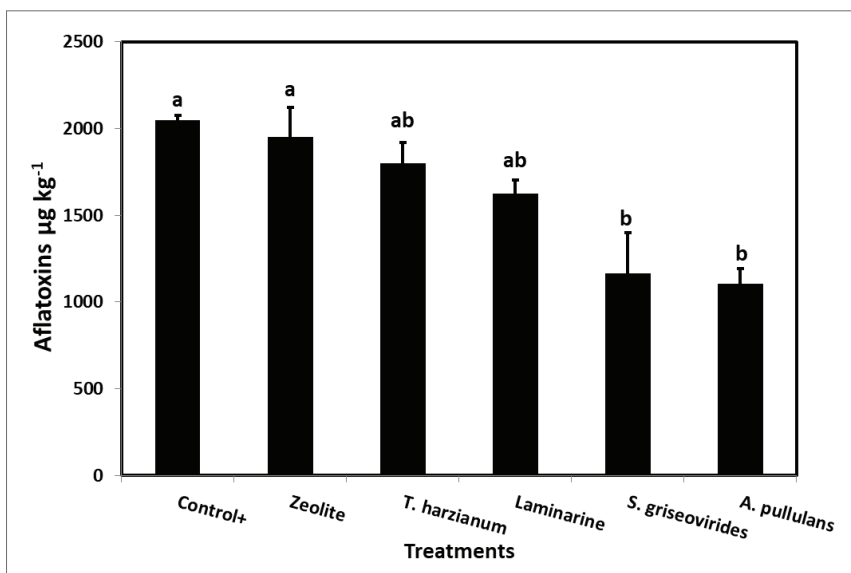

FIGURE 4 | Mean AFs content $\left(\mu \mathrm{kg}^{-1}\right)$ in maize kernels from field grown plants treated with different commercial biopesticides/biostimulants and then artificially inoculated with $A$. flavus strain A6.10. Columns accompanied by different letters are significantly different $(p \leq 0.05)$ according to Tukey's HSD test. Vertical bars indicate standard errors of the means. The results represent the average AFs content for 2014 and 2015.

\section{DISCUSSION}

Mycotoxins, especially aflatoxins, are one of the major worldwide threats to food quality and safety of the population feed. The public concern of pesticides and their residues as an emerging threat in food and environment have increased the interest in alternative methods for disease control both at pre- and post-harvest stages. In Europe, there is a lack of commercial products (biological or chemicals) to prevent AFs in maize despite the fact that EU sets very strict rules for the maximum limits of AFs in foods. Based on several studies and the impact of the climate conditions in the life cycle of mycotoxigenic fungi and mycotoxin production (Edlayne et al., 2009; Chulze, 2010; Russell et al., 2010; 
Battilani et al., 2012), a "biological" solution seems to be the only promising solution for the aflatoxin reduction combined with good agricultural practices, sustainable IPM strategies and agricultural precision technologies.

The use of certain bacteria, yeasts, and other antagonistic fungi to reduce $\mathrm{AF}$ contamination has been documented in maize, groundnut, and other crops (Nesci et al., 2005; Alaniz Zanon et al., 2013; Morteza et al., 2013; Zhao et al., 2014; Sivparsad and Laing, 2016; Siahmoshteh et al., 2017). In this study, six commercial biological products were evaluated for their ability to control A. flavus and aflatoxin production. Zeolite, Vacciplant ${ }^{\circledR}$, Serenade Max $^{\circledR}$, and Mycostop ${ }^{\circledR}$ inhibited effectively the sporulation of all three $A$. flavus toxigenic strains in vitro by $48.2-63.1 \%$ with no statistically significant difference among the strains. In contrary, Botector ${ }^{\circledR}$ and Trianum $^{\circledR}$ did not provide any significant inhibition in the sporulation of the three toxigenic strains when they were tested in vitro, but led to a significant reduction of AFB1 and Aspergillus ear rot severity in the field under a high $A$. flavus inoculum pressure per plant. Moreover, Mycostop ${ }^{\circledR}$ has the ability to inhibit the AFB1 content in maize field experiments, despite the fact that it did not suppress the ear rot severity by more than $10 \%$. In-vitro tests do not resemble the natural environmental variation but they are always essential for the first screening of all plant protection products.

The two-year field experiment showed that when we applied the biological products Botector ${ }^{\circledR}$ (A. pullulans) and Mycostop ${ }^{\circledR}$ (S. griseovirides) twice during the silk stage, they were able to reduce AF production. The most effective commercial biopesticide was Botector ${ }^{\circledR}$ that showed an inhibition of Aspergillus ear rot severity by $22 \%$ and a significant reduction of aflatoxin content by $46 \%$. Bacillus spp. and yeasts are growing at a faster rate than A. flavus and as a consequence, they can demonstrate a higher biocontrol efficacy during the first steps of incubation (Siahmoshteh et al., 2017). Based on several studies, the mode of action of Bacillus strains is the inhibition of mycelial growth and the antibiosis (Baysal et al., 2008; Zhao et al., 2014). Other studies, by Chan et al. (2003), mention that Bacillus strains have the same mode of action for other fungi except A. flavus, such as Fusarium sp., Alternaria sp., and Phytophthora sp. Mannaa et al. (2017) mentioned that some Bacillus strains reduced significantly the aflatoxin production in rice grains produced by $A$. flavus due to their volatiles. In our study, Serenade Max $^{\otimes}$ (Bacillus subtilis) did not reduce the AFB1 content when tested by TLC.

Liu et al. (2013) reported that yeasts, such as A. pullulans, grow rapidly and as a result, deplete available nutrients and physically occupy the given space. After the colonization, other modes of action can play a significant role in concert with nutrient competition and niche exclusion to disclose decay management (Droby et al., 2000, 2009; Wisniewski et al., 2007). Moreover, the study of Ponsone et al. (2011) shows that some yeasts are able to deliver promising results against the grape rot by Aspergillus section Nigri. In accordance with our study, Dimakopoulou et al., 2008 mention that an A. pullulans isolation offered a significant reduction on A. carbonarius strain in grapes. Moreover, Prasongsuk et al. (2013) found that the components that lead to a reduction in AFB1 content are the aureobasidins.

Concerning Vacciplant ${ }^{\circledR}$ that is based on laminarine, Hu et al. (2011) mention that a specific concentration of laminarine could decrease the infection of peanut seeds by A. flavus as well as the contamination by AFB1. In the present study, we found that laminarine inhibits conidia germination but did not provide any protection against AFB1 biosynthesis.

In our studies, Trianum ${ }^{\circledR}$ (T. harzianum) led to a significant reduction of conidia production in vitro, but in the field experiments, did not significantly reduce the Aspergillus ear rot severity or the aflatoxin production. The mode of action of T. harzianum is based on its ability to successfully colonize a wide array of ecological niches (Schuster and Schmoll, 2010). The competitive exclusion of T. harzianum involves the utilization of limited resources, and as a result, the pathogen is unable to grow. Alamene (2015) found that Trichoderma strains from a commercial biocontrol product (Tusal) ${ }^{\circledR}$ can effectively inhibit toxigenic A. flavus species and AFB1 concentrations in vitro and in planta, to a level below that recommended by the European Commission of $15 \mathrm{ppb}$ in peanuts. Gachomo and Kotchoni (2008) mention that two strains of T. harzianum and two strains of $T$. viride were found to efficiently suppress the growth of peanut molds and to significantly reduce aflatoxins (AFB1 and AFB2), contents in infected peanut kernels due to their extracellular enzymatic activities and mycoparasitism. Abdel-Megeed (2013) found that a T. harzianum strain provided significant suppression of AFB1 content by $91.2 \%$ in in vitro tests and Sivparsad and Laing (2016) found that T. harzianum colonizes the silk of sweet corn by inhibiting the $A$. flavus infection.

Finally, our results showed that zeolite has the capacity to inhibit conidia germination in vitro. These data are in agreement with the study of Savi et al. (2017) who present that the ion-exchanged zeolites with $\mathrm{Li}^{+}$and $\mathrm{Cu}^{2+}$ have antifungal activity against $A$. flavus, including negative effects on conidia germination, hyphae morphological alterations, and inhibition of AFB1 production. Another study by Marković et al. (2015) indicates that zeolite can provide AFB1 adsorption. However, in our experiments, zeolite did not reduce AFB1 content neither in the field nor in in vitro tests. These results show that probably the application dose and application timing are crucial factors in the efficacy of zeolite in planta.

To date, there have been several studies demonstrating the efficacy of some microorganisms against A. flavus (Mannaa et al., 2017; Shakeel et al., 2018; Zeidan et al., 2018; Feng et al., 2019; Kagot et al., 2019; Mwakinyali et al., 2019; Peromingo et al., 2019). However, none of these studies have been conducted at field level and their tested microorganisms are not commercial formulations. Several factors can influence the efficacy of the biocontrol agents such as the cultivar response, the plant nutrition, the environmental variables, and the climate change. Furthermore, experiments about the right application and the appropriate number of application and dose could help to improve their efficacy against aflatoxins. 
The European Commission suggests that, in southern Europe, climate change may lead to temperature increases of $4-5^{\circ} \mathrm{C}$, in combination with increased drought periods (García-Cela et al., 2011; Battilani et al., 2012), conditions that will favor the production of aflatoxins in maize and other crops. An integrated approach of pre-harvest biological control, in conjunction with other post-harvest management strategies constitutes a very promising method for a long-term reduction in aflatoxin contamination in maize.

\section{CONCLUSIONS}

The findings of these studies demonstrated for the first time, the potential of commercial non-chemical products (e.g., Botector $^{\circledR}$ and Mycostop ${ }^{\circledR}$ ) to suppress disease ear rot severity symptoms and decrease significantly AFB1 content in maize fields. Taking everything into account, the biological control of aflatoxigenic fungi, the control of insects, and the investigation on new maize aflatoxin tolerant hybrids/varieties along with effective chemical products (Lagogianni and Tsitsigiannis, 2018), disease forecasting models and decision support systems can lead to a successful IPM system in order to eliminate the aflatoxins problem in maize and other crops.

\section{REFERENCES}

Abdel-Megeed, A. (2013). Antagonistic activities of some fungal strains against the toxigenic Aspergillus flavus isolate and its aflatoxins productivity. J. Pure App. Microbiol. 7, 169-178.

Alamene, A. (2015). Effects of plant essential oils and biocontrol agents on the growth of and mycotoxin production by Aspergillus spp. on groundnut. PhD thesis. Nottingham, UK: University of Nottingham.

Alaniz Zanon, M. S., Chiotta, M. L., Giaj-Merlera, G., Barros, G., and Chulze, S. (2013). Evaluation of potential biocontrol agent for aflatoxin in Argentinean peanuts. Int. J. Food Microbiol. 162, 220-225. doi: 10.1016/j.ijfoodmicro.2013.01.017

Atehnkeng, J., Ojiambo, P. S., Cotty, P. J., and Bandyopadhyay, R. (2014). Field efficacy of a mixture of atoxigenic Aspergillus flavus link: $\mathrm{Fr}$ vegetative compatibility groups in preventing aflatoxin contamination in maize (Zea mays L.). Biol. Control 72, 62-70. doi: 10.1016/j.biocontrol.2014.02.009

Battilani, P., Rossi, V., Giorni, P., Pietri, A., Gualla, A., Van der Fels-Klerx, H. J., et al. (2012). Modelling, predicting and mapping the emergence of aflatoxins in cereals in the EU due to climate change. Scientific report submitted to the EuropeanFood Safety Authority (EFSA).

Baysal, O., Calıskan, M., and Yesilova, O. (2008). An inhibitory effect of a new Bacillus subtilis strain (EU07) against Fusarium oxysporum f. sp. radicislycopersici. Physiol. Mol. Plant Pathol. 73, 25-32. doi: 10.1016/j. pmpp.2008.11.002

Bennett, J. W., and Klich, M. (2003). Mycotoxins. Clin. Microbiol. Rev. 16, 497-516. doi: 10.1128/CMR.16.3.497-516.2003

Bosco, F., and Mollea, C. (2012). Mycotoxins in food. Rijeka: InTech Open Access Publisher.

CAST (2003). Mycotoxins: Risk in plant. Ames, Iowa, USA: Animal and Human Systems.

Chan, Y.-K., McCormick, W. A., and Seifert, K. A. (2003). Characterization of an antifungal soil bacterium and its antagonistic activities against Fusarium species. Can. J. Microbiol. 49, 253-262. doi: 10.1139/w03-033

Chourasia, H. K., and Sah, P. K. (2017). "Control of aflatoxin biosynthesis in peanut with geocarposphere bacteria: a biotechnological approach for sustainable development" in Applications of biotechnology for sustainable development. eds. K. Mukhopadhyay, A. Sachan, and M. Kumar (Singapore: Springer).

\section{DATA AVAILABILITY STATEMENT}

The datasets generated for this study are available on request to the corresponding author.

\section{AUTHOR CONTRIBUTIONS}

CL performed the experiments, analyzed the data, and wrote the manuscript. DT conceived the study, analyzed the data, and edited the manuscript.

\section{FUNDING}

This research was partially funded by the Program of Postgraduate Studies of the Department of Crop Science of the Agricultural University of Athens, Greece.

\section{ACKNOWLEDGMENTS}

The authors are grateful to BIO-FERM, Koppert, BASF, and GOEMAR for providing the commercial formulations used in this study.

Chulze, S. N. (2010). Strategies to reduce mycotoxin levels in maize during storage: a review. Food Addit. Contam. 27, 651-657. doi: 10.1080/ 19440040903573032

Dimakopoulou, M., Tjamos, S. E., Antoniou, P. P., Pietri, A., Battilani, P., Avramidis, N., et al. (2008). Phyllosphere grapevine yeast Aureobasidium pullulans reduces Aspergillus carbonarius (sour rot) incidence in wine-producing vineyards in Greece. Biol. Control 46, 158-165. doi: 10.1016/j.biocontrol.2008.04.015

Dorner, J. W. (2004). Biological control of aflatoxin crop contamination. Toxin Rev. 10, 787-792. doi: 10.1081/TXR-200027877

Dorner, J. W., and Cole, R. J. (2002). Effect of application of non-toxigenic strains of Aspergillus flavus and A. parasiticus on subsequent aflatoxin contamination of peanuts in storage. J. Stored Prod. Res. 38, 329-339. doi: 10.1016/S0022-474X(01)00035-2

Dorner, J. W., and Horn, B. W. (2007). Separate and combined applications of non-toxigenic Aspergillus flavus and Aspergillus parasiticus for biocontrol of aflatoxin in peanuts. Mycopathologia 163, 215-223. doi: 10.1007/ s11046-007-9004-0

Droby, S., Wilson, C., Wisniewski, M., and El Ghaouth, A. (2000). "Biologically based technology for the control of postharvest diseases of fruits and vegetables" in Microbial food contamination. eds. C. Wilson and S. Droby (Boca Raton, FL, USA: CRC Press), 187-206.

Droby, S., Wisniewski, M., Macarisin, D., and Wilson, C. (2009). Twenty years of postharvest biocontrol research: is it time for a new paradigm? Postharvest Biol. Technol. 52, 137-145. doi: 10.1016/j.postharvbio.2008.11.009

Edlayne, G., Simone, A., and Felicio, J. D. (2009). Chemical and biological approaches for mycotoxin control: a review. Recent Pat. Food Nutr. Agric. 1, 155-161. doi: 10.2174/2212798410901020155

Feng, J., Dou, J., Wu, Z., Yin, D., and Wu, W. (2019). Controlled release of biological control agents for preventing aflatoxin contamination from starchalginate beads. Molecules 24:1858. doi: 10.3390/molecules 24101858

Gachomo, E., and Kotchoni, S. O. (2008). The use of Trichoderma harzianum and T. viride as potential biocontrol agents against peanut microflora and their effectiveness in reducing aflatoxin contamination of infected kernels. Biotechnology 7, 439-447. doi: 10.3923/biotech.2008.439.447

García-Cela, E., Ramos, A. J., Sanchis, V., and Marin, S. (2011). Ochratoxigenic moulds and effectiveness of grape field antifungals in a climatic change scenario. J. Sci. Food Agric. 92, 1455-1461. doi: 10.1002/jsfa.4726 
Hu, L., Li, H., Sun, J., and Jeng, J. (2011). Effect of laminarin on Aspergillus flavus growth and aflatoxin production. doi: 10.4028/www.scientific.net/ AMR.343-344.1168

Kagot, V., Okoth, S., De Boevre, M., and De Saeger, S. (2019). Biocontrol of Aspergillus and Fusarium mycotoxins in Africa: benefits and limitations. Toxins 11:109. doi: 10.3390/toxins11020109

Lagogianni, C. S., and Tsitsigiannis, D. I. (2018). Effective chemical management for prevention of aflatoxins in maize. Phytopathol. Mediterr. 57, 186-197. doi: 10.14601/Phytopathol_Mediterr-22492

Liu, J., Sui, Y., Wisniewski, M., Samir Droby, S., and Liu, Y. (2013). Review: utilization of antagonistic yeasts to manage postharvest fungal diseases of fruit. Int. J. Food Microbiol. 167, 153-160. doi: 10.1016/j.ijfoodmicro.2013.09.004

Mannaa, M., Oh, J. Y., and Kim, K. D. (2017). Biocontrol activity of volatileproducing Bacillus megaterium and Pseudomonas protegens against Aspergillus flavus and aflatoxin production on stored rice grains. Mycobiology 45, 213-219. doi: 10.5941/MYCO.2017.45.3.213

Marković, M., Daković, A., Rottinghaus, G. E., Stojanovic, M., Dondur, V., Kragovic, M., et al. (2015). Aflatoxin B1 adsorption by the natural aluminosilicates - concentrate of montmorillonite and zeolite. Hemijska Industrija 70, 58-58. doi: 10.2298/HEMIND150515058M

Mauro, A., Garcia-Cela, E., Pietri, A., Cotty, P. J., and Battilani, P. (2018). Biological control products for aflatoxin prevention in Italy: commercial field evaluation of atoxigenic Aspergillus flavus active ingredients. Toxins 10, pii: E30. doi: 10.3390/toxins 10010030

Morteza, A., Aliabaddi, F., Alikhani, M., and Mohammadi, R. K. (2013). Biological control of aflatoxins. Eur. J. Exp. Biol. 3, 162-166.

Mwakinyali, S. E., Dinga, X., Minga, Z., Tonga, W., Zhanga, Q., and Li, P. (2019). Recent development of aflatoxin contamination biocontrol in agricultural products. Biol. Control 128, 31-39. doi: 10.1016/j.biocontrol.2018.09.012

Nesci, A., Bluma, R. V., and Etcheverry, M. G. (2005). In vitro selection of maize rhizobacteria to study potential biological control of Aspergillus section Flavi and aflatoxin production. Eur. J. Plant Pathol. 113, 159-171. doi: $10.1007 /$ s10658-005-5548-3

O'Donnell, K. (2000). Molecular phylogeny of the Nectria haematococca-Fusarium solani species complex. Mycologia 92, 919-938. doi: 10.2307/3761588

Peromingo, B., Andrade, M. J., Delgado, J., Sánchez-Montero, L., and Núñez, F. (2019). Biocontrol of aflatoxigenic Aspergillus parasiticus by native Debaryomyces hansenii in dry-cured meat products. Food Microbiol. 82, 269-276. doi: 10.1016/j. fm.2019.01.024

Ponsone, M. L., Chiotta, M. L., Combina, M., Dalcero, A., and Chulze, S. (2011). Biocontrol as a strategy to reduce the impact of ochratoxin A and Aspergillus section Nigri in grapes. Int. J. Food Microbiol. 151, 70-77. doi: 10.1016/j.ijfoodmicro.2011.08.005

Prasongsuk, S., Ployngam, S., Wacharasindhu, S., and Punnapayak, H. (2013). Effects of sugar and amino acid supplementation on Aureobasidium pullulans NRRL 58536 antifungal activity against four Aspergillus species. Appl. Microbiol. Biotechnol. 97, 7821-7830. doi: 10.1007/s00253-013-5069-5

RASFF/Rapid Alert System For Food and Feed for the European Union (2008). https://ec.europa.eu/food/sites/food/files/safety/docs/rasff_annual_report_2008_ en.pdf

Reid, L. M., Nicol, R. W., Ouellet, T., Savard, M., Miller, J. D., Young, J. C., et al. (1999). Interaction of Fusarium graminearum and F. moniliforme in maize ears: disease progress, fungal biomass, and mycotoxin accumulation. Phytopathology 89, 1028-1037. doi: 10.1094/PHYTO.1999.89.11.1028

Russell, R., Paterson, M., and Lima, N. (2010). How will climate change affect mycotoxins in food? Food Res. Int. 43, 1902-1914. doi: 10.1016/j.foodres.2009.07.010
Savi, G., Cardosso, W., Furtado, B., Bortolotto, T., Agostin, L., Nones, J., et al. (2017). New ion-exchanged zeolite derivatives: antifungal and antimycotoxin properties against Aspergillus flavus and aflatoxin B1. Mat. Res. Expr. 4:085401. doi: $10.1088 / 2053-1591 /$ aa84a5

Schuster, A., and Schmoll, M. (2010). Biology and biotechnology of Trichoderma. Appl. Microbiol. Biotechnol. 87, 787-799. doi: 10.1007/s00253-010-2632-1

Scott, P. M. (1995). "Natural toxins" in The official methods of analysis of AOAC international. ed. P. A. Cunniff (Maryland, USA: Gaithersburg), 1-51.

Shakeel, Q., Lyu, A., Zhang, J., Wu, M., Li, G., Hsiang, T., et al. (2018). Biocontrol of Aspergillus flavus on peanut kernels using Streptomyces yanglinensis 3-10. Front. Microbiol. 9:1049. doi: 10.3389/fmicb.2018.01049

Siahmoshteh, F., Siciliano, I., Banani, H., Hamidi-Esfahania, Z., RazzaghiAbyanehd, M., Gullino, M.-L., et al. (2017). Efficacy of Bacillus subtilis and Bacillus amyloliquefaciens in the control of Aspergillus parasiticus growth and aflatoxins production on pistachio. Int. J. Food Microbiol. 254, 47-53. doi: 10.1016/j.ijfoodmicro.2017.05.011

Sivparsad, B., and Laing, M. D. (2016). Pre-harvest silk treatment with Trichoderma harzianum reduces aflatoxin contamination in sweetcorn. J. Plant Dis. Prot. 123, 285-293. doi: 10.1007/s41348-016-0037-9

Udomkun, P., Wiredu, A., Nagle, M., Müller, J., Vanlauwe, B., and Bandyopadhyay, R. (2017). Innovative technologies to manage aflatoxins in foods and feeds and the profitability of application - a review. Food Control 76, 127-138. doi: 10.1016/j.foodcont.2017.01.008

Vaughan, A., O'Sullivan, T., and van Sinderen, D. (2005). Enhancing the microbiological stability of malt and beer - a review. J. Inst. Brew. 111, 355-371. doi: 10.1002/j.2050-0416.2005.tb00221.x

Wisniewski, M., Wilson, C., Droby, S., Chalutz, E., El Ghaouth, A., and Stevens, C. (2007). "Postharvest biocontrol: new concepts and applications" in Biological control: A global perspective. eds. C. Vincent, M. S. Goettal, and G. Lazarovits (Cambridge, MA, USA: CABI), 262-273.

Yin, Y., Yan, L.-Y., Jiang, J.-H., and Zhong-hua Ma, Z.-H. (2008). Biological control of aflatoxin contamination of crops. J Zhejiang Univ Sci B 9, 787-792. doi: 10.1631/jzus.B0860003

Zeidan, R., Ul-Hassan, Z., Al-Thani, R., Balmas, V., and Jaoua, S. (2018). Application of low-fermenting yeast Lachancea thermotolerans for the control of toxigenic fungi Aspergillus parasiticus, Penicillium verrucosum and Fusarium graminearum and their mycotoxins. Toxins 10:242. doi: $10.3390 /$ toxins 10060242

Zhao, Y., Selvaraj, J. N., Xing, F., Zhou, L., Wang, Y., Song, W., et al. (2014). Antagonistic action of Bacillus subtilis strain SG6 on Fusarium graminearum. PLoS One 9:e92486. doi: 10.1371/journal.pone.0115872

Zummo, N., and Scott, G. E. (1989). Evaluation of field inoculation techniques for screening maize genotypes against kernel infection by Aspergillus flavus in Mississippi. Plant Dis. 73, 313-316. doi: 10.1094/PD-73-0313

Conflict of Interest: The authors declare that the research was conducted in the absence of any commercial or financial relationships that could be construed as a potential conflict of interest.

Copyright (c) 2019 Lagogianni and Tsitsigiannis. This is an open-access article distributed under the terms of the Creative Commons Attribution License (CC $B Y)$. The use, distribution or reproduction in other forums is permitted, provided the original author(s) and the copyright owner(s) are credited and that the original publication in this journal is cited, in accordance with accepted academic practice. No use, distribution or reproduction is permitted which does not comply with these terms. 